\title{
Cenizas de cascarilla de arroz para la activación alcalina de cementantes binarios (ceniza volante/escoria de alto horno)
}

\author{
Rice husk ash for alkali activation \\ binary blends (fly ash/blast furnace slag)
}

\author{
Jhon Cárdenas Pulido ${ }^{1}$, John Wilfer Aperador Chaparro ${ }^{1}$, Willian Aperador Chaparro ${ }^{1}$, \\ Manuel Jonathan Pinzón Cárdenas ${ }^{2}$, Kervin Chunga ${ }^{3}$, Michel Ángelo Ospina Guzman ${ }^{4}$
}

\footnotetext{
${ }^{1}$ Facultad de Ingeniería, Universidad Militar Nueva Granada, Carrera 11 No. 101-80, Bogotá, Santa fé, Colombia

${ }^{2}$ Universidad ECCI, Bogotá, Santa Fé, Colombia.

${ }^{3}$ Facultad de Ciencias Matemáticas, Físicas y Químicas, Departamento de Construcciones Civiles, Universidad Técnica de Manabí, UTM, Av. José María Urbina, Portoviejo, Manabí, Ecuador.

${ }^{4}$ Casta roja agroindustrial S. A., Guayas, Guayas, Ecuador.

e-mail: u1100907@unimilitar.edu.co,g.ing.materiales@gmail.com, kchunga@utm.edu.ec, michelospina@gmail.com
}

\section{RESUMEN}

Se fabricaron morteros de activación alcalina basados en ceniza volante clase $\mathrm{F}$ y escoria de alto horno, con el fin de estudiar el efecto de una fuente alternativa de sílice sobre sus propiedades de fluidez y resistencia a compresión. Ceniza de cascarilla de arroz y silicato de sodio, en combinación con hidróxido de sodio, fueron las soluciones químicas empleadas para la activación alcalina de los morteros. La información mineralógica y estructural de los sistemas activados alcalinamente fue obtenida mediante difracción de rayos X (DRX), mientras que el análisis de sus propiedades en estado fresco se llevó a cabo a través del estudio de la fluidez. Además se evaluaron las propiedades mecánicas de las morteros a 28 días por médio del ensayo de resistencia a compresión. Se encontró que los morteros activados con ceniza de cascarilla de arroz en combinación con hidróxido de sodio presentaron resistencias a compresión hasta 25\% mayores en comparación con los morteros activados con silicato de sodio /hidróxido de sodio. Finalmente fueron propuestas ecuaciones para la predicción de las resistencias a compresión de los morteros en función del tipo de activador. Este estudio concluye que es posible utilizar cenizas de cascarilla de arroz como una fuente alternativa de sílice para procesos de activación alcalina.

Palavras-chave: Ceniza de cascarilla de arroz, activación alcalina, ceniza volante, escoria de alto horno, resistencia a compresión.

\begin{abstract}
Alkali activated mortars made of class F fly ash and blast furnace slag were cast, in order to study the effect of an alternative source of silica on its properties of fluidity and compressive strength. Rice husk ash and sodium silicate solution, mixed with sodium hydroxide, were used for activation of mortars. The mineralogical and structural information of alkali activated systems was obtained by X-ray diffraction (XRD), while the analysis of fresh properties was carried out by means of fluidity test. The mechanical properties of mortars were assessed by 28 days compressive strength test. It was found that mortars activated with rice husk ash plus sodium hydroxide showed compressive strengths up to $25 \%$ higher that those activated with sodium silicate / sodium hydroxide. Finally, equations were proposed for the prediction of compressive strengths of mortars according to the type of activator. This study concludes that it is possible the use of rice husk ash as an alternative source of silica in alkaline activation process.
\end{abstract}

Keywords:Rice husk ash, alkaline activation, fly ash, blast furnace slag, compressive strength. 


\section{INTRODUCCIÓN}

Los geopolímeros o sistemas de activación alcalina son materiales constituidos por una fuente de aluminosilicatos y una solución alcalina activante. La fuente de aluminosilicatos puede ser de origen natural como arcillas caoliníticas, cenizas volcánicas, metacaolín etc., u origen residual como cenizas volantes, escorias de siderúrgicas o de alto horno, y otros [1]. Entre los sistemas cementantes activados alcalinamente, las cenizas volantes y escorias granuladas de alto horno han sido los materiales más estudiados. Lo anterior es debido al adecuado proceso de activación que presentan, y a la formación de los productos cementantes que generan, en la escoria por la formación del gel C-A-S-H y en la ceniza volante por la formación del gel N-A-S-H. Ya en estado endurecido, el desempeño mecánico de los sistemas basados en ceniza volante y escoria depende principalmente de la composición química de los agentes activantes, de la naturaleza y calidad de las materias primas y del tipo de curado efectuado.

El componente activante desempeña un rol fundamental en la síntesis de los precursores. Para ese fin, han sido utilizadas mezclas de silicatos e hidróxidos, siendo de gran aceptación la combinación silicato de sodio e hidróxido de sodio a las concentraciones deseadas. En particular, el silicato de sodio ha sido identificado como el promotor de grandes resistencias mecánicas en sistemas de activación alcalina, junto con una permeabilidad reducida y una estructura estable [2] Sin embargo, fabricar silicato de sodio requiere grandes cantidades de energía y el proceso desprende emisiones considerables de $\mathrm{CO}_{2}$ a la atmósfera, por lo que su producción no se considera ni económica ni sostenible. Según Bernal et al. [3], la fabricación del silicato de sodio comprende la calcinación del carbonato de sodio $\left(\mathrm{Na}_{2} \mathrm{CO}_{3}\right)$ y la arena de cuarzo $\left(\mathrm{SiO}_{2}\right)$ a temperaturas entre 1400 y $1500{ }^{\circ} \mathrm{C}$. También Novotny et al. [4] manifiestan que la fabricación de silicato de sodio genera una considerable contaminación del aire debido a emisiones de polvo, óxidos de nitrógeno y de azufre. Se estima que el total de emisiones durante la fabricación de silicato de sodio tradicional equivale a 1,514 $\mathrm{kg}$ de $\mathrm{CO}_{2}$ por cada $1 \mathrm{~kg}$ de silicato de sodio [5]. Así, fuentes alternativas de sílice son requeridas para reducir el impacto económico y ambiental que implica la producción del silicato de sodio, y en esa vía, las cenizas de cascarilla de arroz pueden representar una atractiva opción debido a su elevado contenido de sílice [1,3-7], al considerar que tanto la parte amorfa como la cristalina tienen posibilidad de participar en los procesos de activación alcalina [8].

En línea con los objetivos de previos estudios [1,3-8], el presente trabajo examina los efectos de la ceniza de cascarilla de arroz como fuente alternativa de sílice para la activación alcalina de sistemas binarios ceniza volante/escoria de alto horno. Para esto, fueron llevados a cabo sobre morteros activados con silicato de sodio o ceniza de cascarilla de arroz, en combinación con hidróxido de sodio, ensayos de laboratorio en estado fresco y endurecido para su caracterización, y los resultados obtenidos fueron comparados para cada tipo de activador. Los resultados experimentales se utilizaron con el fin de proponer ecuaciones que permitan predicir las resistencias a compresión de los sistemas binarios analizados, para cada tipo de activador. De este modo, por el empleo de las cenizas de cascarilla de arroz en procesos de activación alcalina, se promueve el uso de un residuo agroindustrial que es comúnmente arrojado a vertederos y fuentes de agua y que se resiste a la degradación natural, lo que causa contaminación al entorno y grandes problemas de disposición.

\section{MATERIALES Y MÉTODOS}

El programa experimental comprendió la elaboración de 8 mezclas binarias de activación alcalina constituidas por 4 mezclas con ceniza de cascarilla de arroz (CCA) y 4 mezclas con silicato de sodio $\left(\mathrm{Na}_{2} \mathrm{SiO}_{3}\right)$ como partes activantes, y diferentes dosificaciones de ceniza volante (FA) y escoria de alto horno (BFS). Posteriormente, se efectuaron ensayos en estado fresco y endurecido sobre las diferentes mezclas fabricadas con el fin de caracterizar sus desempeños tanto físicos como mecánicos.

\subsection{Materiales cementantes}

En este estudio se utilizó ceniza volante clase F proveniente de la planta termoeléctrica de Sochagota (Paipa, Boyacá, Colombia) con un tamaño promedio de partícula de $28 \mu \mathrm{m}$. Fue empleada escoria granulada de alto horno proveniente de la planta de Acerías Paz del Río (Nobsa, Boyacá, Colombia) con un tamaño promedio de partícula de $32 \mu \mathrm{m}$. Asimismo fue utilizada ceniza de cascarilla de arroz obtenida a través del tratamiento térmico de la cascarilla de arroz en horno de combustión espontánea, esta proveniente de la empresa Arrocera la Esmeralda (Jamundí, Valle del Cauca, Colombia). La ceniza de cascarilla de arroz contaba con un tamaño de partícula original de $125 \mu \mathrm{m}$, que posteriormente fue reducido a un tamaño promedio de $25 \mu \mathrm{m}$ por proceso de molienda. La caracterización de las materias primas se realizó por médio de ensayos de fluorescencia y de granulometría laser. La composición química de los materiales se resume en la Tabla 1. De la Tabla 1 se observa que aunque la ceniza de cascarilla de arroz (CCA) cuenta con una cantidad predominante de sílice en 
hasta $91 \%$, el porcentaje de sílice disuelta en una solución $\mathrm{NaOH} 1 \mathrm{~N}$ durante 2 minutos de ebullición fue $32,29 \%$. Este porcentaje de sílice disuelta representa el porcentaje de sílice amorfa o sílice reactiva presente en la ceniza de cascarilla de arroz.

Como material pétreo se empleó arena con módulo de finura 2,9 y un porcentaje de absorción de $0,81 \%$.

Tabla 1: Composición química de los materiales cementantes empleados.

\begin{tabular}{cccc}
\hline COMPUESTO & $\begin{array}{c}\text { FA } \\
\%\end{array}$ & $\begin{array}{c}\text { BFS } \\
\%\end{array}$ & $\begin{array}{c}\text { CCA } \\
\%\end{array}$ \\
\hline $\mathrm{SiO}_{2}$ & 54,30 & 33,70 & 90,93 \\
$\mathrm{Al}_{2} \mathrm{O}_{3}$ & 28,8 & 12,80 & 0,11 \\
$\mathrm{Fe}_{2} \mathrm{O}_{3}$ & 5,30 & 0,48 & 0,19 \\
$\mathrm{CaO}$ & 6,40 & 45,40 & 0,36 \\
$\mathrm{MgO}$ & 0,80 & 1,00 & 0,33 \\
$\mathrm{Na} 2 \mathrm{O}$ & 0,90 & 0,12 & 0,02 \\
$\mathrm{~K}_{2} \mathrm{O}$ & 0,70 & 1,50 & 1,97 \\
$\mathrm{P}_{2} \mathrm{O}_{5}$ & 0,70 & - & - \\
$\mathrm{TiO}_{2}$ & 1,20 & 0,50 & - \\
$\mathrm{MnO}$ & 0,01 & - & - \\
$\mathrm{SO}_{3}$ & 0,92 & - & 0,15 \\
$\mathrm{SiO}_{2} / \mathrm{Al}_{2} \mathrm{O}_{3}$ & 1,88 & 2,63 & - \\
$\mathrm{Inquemados}$ & 6,50 & - & 4,10 \\
\hline
\end{tabular}

\subsection{Mezclas de mortero y descripción de ensayos}

Se fabricaron morteros basados en diferentes combinaciones por peso de ceniza volante clase $\mathrm{F}$ y escoria de alto horno, y fueron activados mediante la combinación hidróxido de sodio y cenizas de cascarilla de arroz /silicato de sodio. Esta combinación de activadores fue asignada con base en los estudios de Criado et al.[9].

De este modo, 4 mezclas de mortero fueron activadas por la combinación $85 \% \mathrm{NaOH} 14 \mathrm{M}+15 \%$ cenizas de cascarilla de arroz para alcanzar una relación $\mathrm{L} / \mathrm{S}=0.20$, y 4 mezclas de mortero fueron activadas por la combinación $85 \% \mathrm{NaOH} 14 \mathrm{M}+15 \%$ silicato de sódio para lograr una relación L/S=0.25. Las relaciones líquido/sólido (L/S) de los morteros fueron calculadas con base en las proporciones de mezcla y la composición química de las materias primas y activadores. Las proporciones de las mezclas se resumen en la Tabla 2. En la Tabla 2, las abreviaciones FA, BFS y CCA se utilizaron para identificar a los materiales ceniza volante, escoria de alto horno y ceniza de cascarilla de arroz, respectivamente. También fueron introducidos a la nomenclatura los porcentajes de reemplazo del material cementante principal: por ejemplo, FA8-BFS2 representa la mezcla de $80 \%$ ceniza volante y $20 \%$ escoria del alto horno; FA4-BFS6 representa la mezcla de $40 \%$ ceniza volante y $60 \%$ escoria de alto horno; FA2-BFS 8 representa la mezcla de $20 \%$ ceniza volante y $80 \%$ escoria del alto horno. Por otro lado, los parámetros de relaciones molares principales para las mezclas de mortero se muestran en la Tabla 3. Para los morteros activados con cenizas de cascarilla de arroz en combinación con hidróxido de sodio, las relaciones molares de la Tabla 3 se calcularon con base en el contenido amorfo o reactivo de la ceniza de cascarilla de arroz.

El silicato de sodio empleado fue de tipo industrial con una composición 9,1\% $\mathrm{Na}_{2} \mathrm{O}, 27,5 \% \mathrm{SiO}_{2}$ y $63,4 \% \mathrm{H}_{2} \mathrm{O}$ y módulo $\mathrm{SiO}_{2} / \mathrm{Na}_{2} \mathrm{O}$ de 3,02. La solución de hidróxido de sodio fue preparada en condiciones controladas de temperatura $23^{\circ} \mathrm{C}$ y humedad relativa $65 \%$, disolviendo las lentejas Panreac PA-ACS-ISO (98\% de pureza) [10] en agua destilada para obtener la concentración 14M deseada. Las soluciones activantes hidróxido de sódio/cenizas de cascarilla de arroz e hidróxido de sódio/ silicato de sodio fueron premezcladas y almacenadas en condiciones de humedad y temperatura ambiente durante 24 horas, previo a la fabricación de los morteros.

Para la fabricación de los morteros, los agregados y materiales cementantes fueron mezclados en una olla mezcladora durante un tiempo de cinco minutos, y luego sobre los materiales secos se agregó la cantidad correspondiente de líquido activante para continuar con el proceso de mezclado a una velocidad de $22 \mathrm{rpm}$ durante otros cinco minutos. Cada mezcla en estado fresco fue vertida en moldes, apisonada y compactada siguiendo los procedimientos descritos en la norma ASTM-C-109M (2016) [11]. Los especímenes se desmoldaron luego de 24 horas de su fabricación y a continuación fueron curados bajo un régimen de $85{ }^{\circ} \mathrm{C}$ de temperatura durante un periodo de 24 horas, con el fin de garantizar el desarrollo de las resistencias mecáni- 
cas. Posteriormente los especímenes fueron desmoldados y alojados en un cuarto de almacenamiento con temperatura ambiente hasta el día del ensayo.

Fueron llevados a cabo sobre los morteros ensayos de caracterización de las propiedades físicomecánicas. Estos ensayos se realizaron con el objeto de determinar la influencia de la ceniza de cascarilla de arroz como parte activante, sobre las propiedades en estado fresco y endurecido de las mezclas fabricadas, es decir, modificación de su resistencia y desempeño.La fluidez de los morteros en estado fresco para las diferentes mezclas binarias fue determinada con el procedimiento de la norma ASTM-C-1437 (2015) [12]. La resistencia a compresión de los morteros se determinó a partir de los especímenes en forma de cubos de $5 \mathrm{~cm}$ de lado, a edad de 28 días, siguiendo el procedimiento de la norma ASTM-C-109M (2016) [11]. La configuración del ensayo y la falla característica de un espécimen se muestran en la Figura 1.

Tabla 2: Proporciones de las mezclas de mortero.

\begin{tabular}{ccccccccc}
\hline ACTIVADOR & ID. MEZCLA & $\begin{array}{c}\text { FA } \\
\left(\mathbf{k g} / \mathbf{m}^{3}\right)\end{array}$ & $\begin{array}{c}\text { BFS } \\
\left(\mathbf{k g} / \mathbf{m}^{3}\right)\end{array}$ & $\begin{array}{c}\text { AGREGADO } \\
\mathbf{F I N O}\left(\mathbf{k g} / \mathbf{m}^{3}\right)\end{array}$ & $\begin{array}{c}\mathbf{C C A} \\
\left(\mathbf{k g} / \mathbf{m}^{3}\right)\end{array}$ & $\begin{array}{c}\mathbf{N a}_{2} \mathrm{SiO}_{3} \\
\left(\mathbf{k g} / \mathbf{m}^{3}\right)\end{array}$ & $\begin{array}{c}\mathbf{N a O H} \\
\left(\mathbf{k g} / \mathbf{m}^{3}\right)\end{array}$ & $\begin{array}{c}\text { AGUA, } \\
\text { ADICIONAL } \\
\left(\mathbf{k g} / \mathbf{m}^{3}\right)\end{array}$ \\
\hline & FA8-BFS2 & 360 & 90 & 675 & 37 & - & 210 & 1 \\
$85 \% \mathrm{NaOH}$ & FA6-BFS4 & 270 & 180 & 675 & 37 & - & 210 & 5 \\
$15 \% \mathrm{CCA}$ & FA4-BFS6 & 180 & 270 & 675 & 37 & - & 210 & 8 \\
& FA2-BFS8 & 90 & 360 & 675 & 37 & - & 210 & 11 \\
\hline & FA8-BFS2 & 360 & 90 & 675 & - & 37 & 210 & - \\
$85 \% \mathrm{NaOH}_{15} \mathrm{Na}_{2} \mathrm{SiO}_{3}$ & FA6-BFS4 & 270 & 180 & 675 & - & 37 & 210 & - \\
& FA4-BFS6 & 180 & 270 & 675 & - & 37 & 210 & - \\
& FA2-BFS8 & 90 & 360 & 675 & - & 37 & 210 & - \\
\hline
\end{tabular}

Tabla 3: Relaciones molares de partida en las mezclas de mortero.

\begin{tabular}{cccccc}
\hline ACTIVADOR & ID. MEZCLA & $\mathbf{S i O}_{\mathbf{2}} / \mathbf{A l}_{\mathbf{2}} \mathbf{O}_{\mathbf{3}}$ & $\mathbf{N a}_{\mathbf{2}} \mathbf{O} / \mathbf{A l}_{\mathbf{2}} \mathbf{O}_{\mathbf{3}}$ & $\mathbf{H}_{\mathbf{2}} \mathbf{O} / \mathbf{N a}_{\mathbf{2}} \mathbf{O}$ & $\mathbf{C a O} / \mathbf{S i O}$ \\
\hline & FA8-BFS2 & 4,48 & 1,84 & 4,18 & 0,22 \\
$85 \% \mathrm{NaOH}$ & FA6-BFS4 & 4,54 & 2,00 & 4,32 & 0,43 \\
$15 \% \mathrm{CCA}$ & FA4-BFS6 & 4,62 & 2,19 & 4,45 & 0,69 \\
& FA2-BFS8 & 4,70 & 2,43 & 4,47 & 0,98 \\
\hline & FA8-BFS2 & 4,45 & 1,90 & 4,75 & 0,22 \\
$85 \% \mathrm{NaOH}$ & FA6-BFS4 & 4,51 & 2,07 & 4,76 & 0,44 \\
$15 \% \mathrm{Na}_{2} \mathrm{SiO}_{3}$ & FA4-BFS6 & 4,58 & 2,27 & 4,77 & 0,69 \\
& FA2-BFS8 & 4,66 & 2,51 & 4,78 & 0,99 \\
\hline
\end{tabular}

Finalmente, caracterizaciones mineralógicas y estructurales de los morteros se realizaron por medio del ensayo de difracción de rayos X, el cual permitió identificar las fases cristalinas presentes en las materias primas y las matrices cementantes, comparando las difracciones particulares de los espectros medidos con los espectros de referencia relacionados en la base de datos COD-2016 (Crystallography Open Database). 


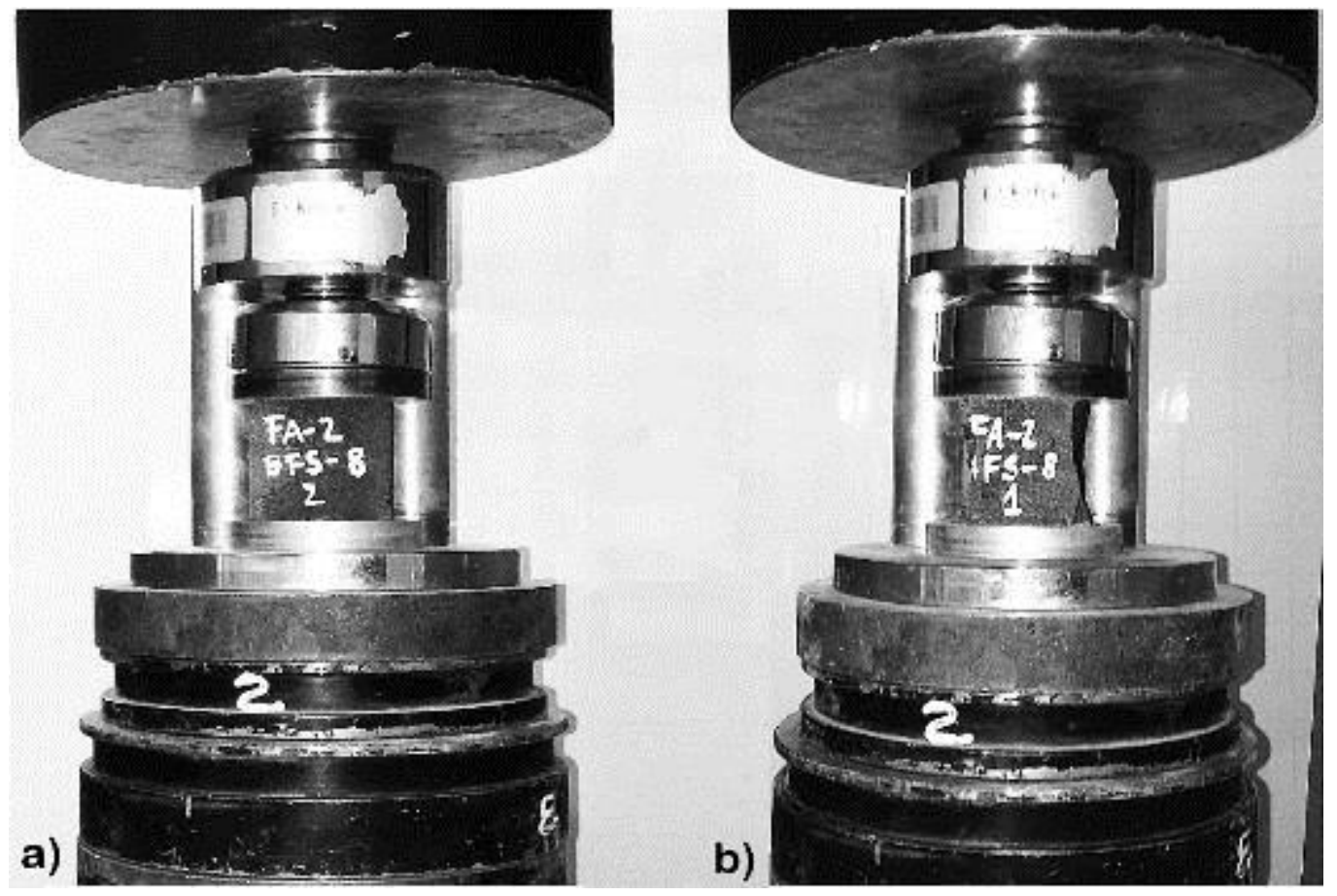

Figura 1: Configuración del ensayo de resistencia a compresión a) espécimen preparado, b) espécimen fallado.

\section{RESULTADOS Y DISCUSIÓN}

En esta sección se presentan los resultados de los ensayos realizados sobre los especímenes de mortero fabricados. A partir de los resultados obtenidos se examinaron las tendencias correspondientes y se formularon modelos de predicción de cada parámetro evaluado, en función del porcentaje de adición de escoria de alto horno utilizado. Para lograr un mejor entendimiento de la influencia de los materiales suplementarios utilizados sobre el desempeño de los morteros, los resultados medidos se comparan con modelos e investigaciones similares.

\subsection{Fluidez}

Los resultados de los ensayos de fluidez sobre las mezclas de mortero activadas com cenizas de cascarilla de arroz / silicato de sódio en combinación con hidróxido de sódio, se muestran en la Figura 2. Las tendencias obtenidas en fluidez, $\mathrm{fl}$, de las mezclas con ceniza de cascarilla de arroz y silicato de sodio se muestran en la Figura 3. 


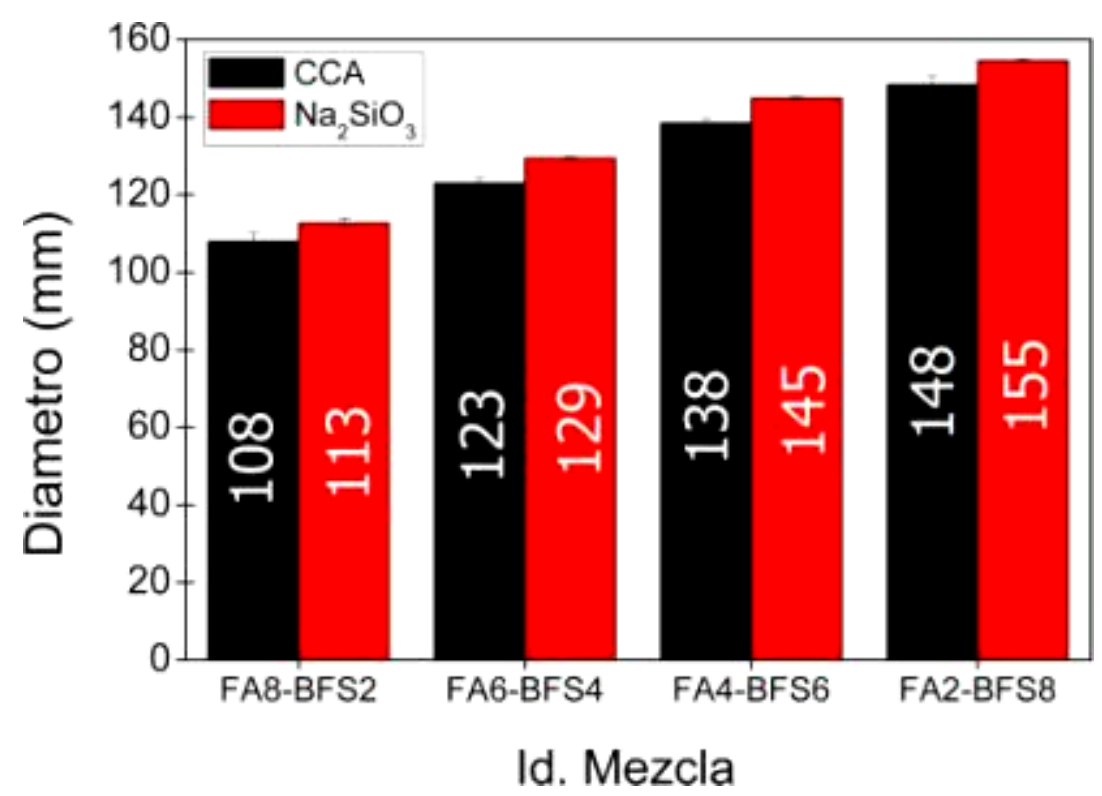

Figura 2: Diámetros de muestra resultantes para las mezclas fabricadas con $\mathrm{CCA} \mathrm{y} \mathrm{Na}_{2} \mathrm{SiO}_{3}$.

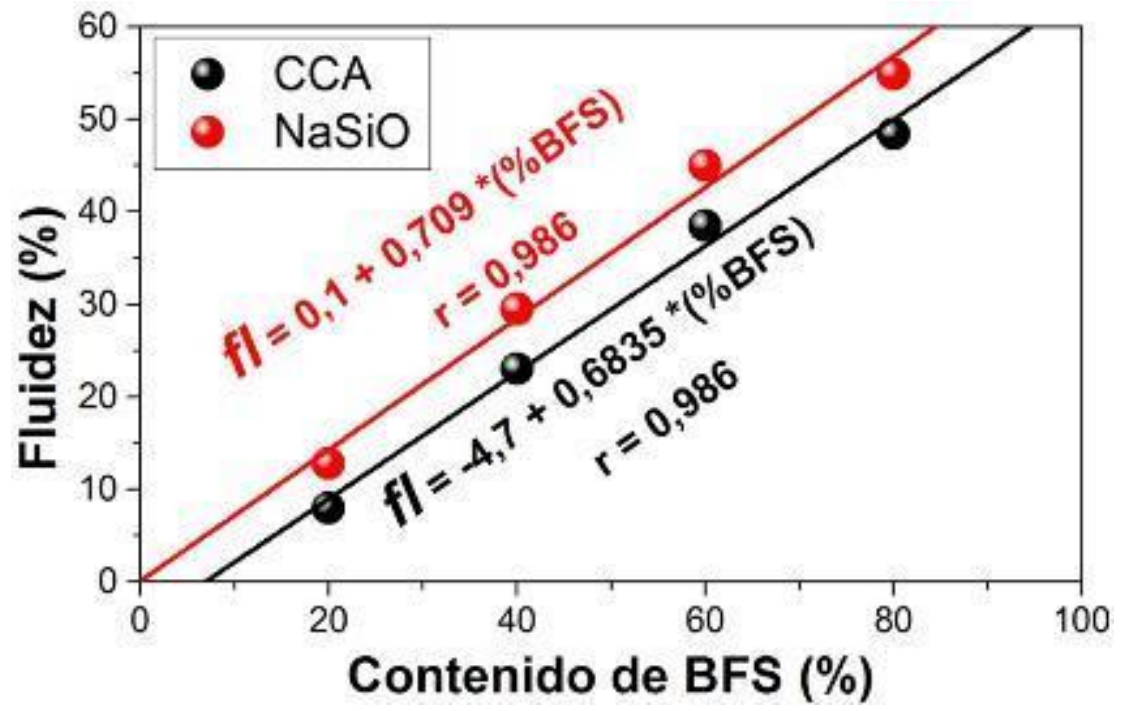

Figura 3: Tendencia en los resultados de fluidez para las mezclas fabricadas.

\subsection{Difracción de rayos $\mathrm{X}$}

Los patrones de difracción de rayos $\mathrm{X}$ obtenidos para los polvos cementantes ceniza volante y escoria de alto horno se muestran en la Figura 4. Como se observa en la Figura 4, el patrón adquirido para la ceniza volante permitió identificar su contenido amorfo, que se refleja por la presencia de una banda extensa y difusa en el rango $2 \theta \approx 19^{\circ}-30^{\circ}$, y se atribuye a la matriz vítrea que confiere las propiedades puzolánicas; adicionalmente, se observó la existencia de 2 fases cristalinas: Cuarzo (SiO, COD Reference Code 96-901-1494) y Mullita (A14SiO8, COD Reference Code 96-900-1322), las cuales se han reportado como las más comunes en la literatura para la ceniza volante, y se encuentran en pequeños porcentajes con respecto al contenido amorfo $(w t \% \approx 5-20 \%)$ [13]. Por otra parte el patrón de difracción de la escoria de alto horno mostrado en la Figura 5 manifestó un comportamiento meramente amorfo, evidenciado en primer lugar por la falta de señales caracte- 
rísticas y en segundo lugar por la presencia de una amplia banda en el rango $2 \theta \approx 26^{\circ}-36^{\circ}$.

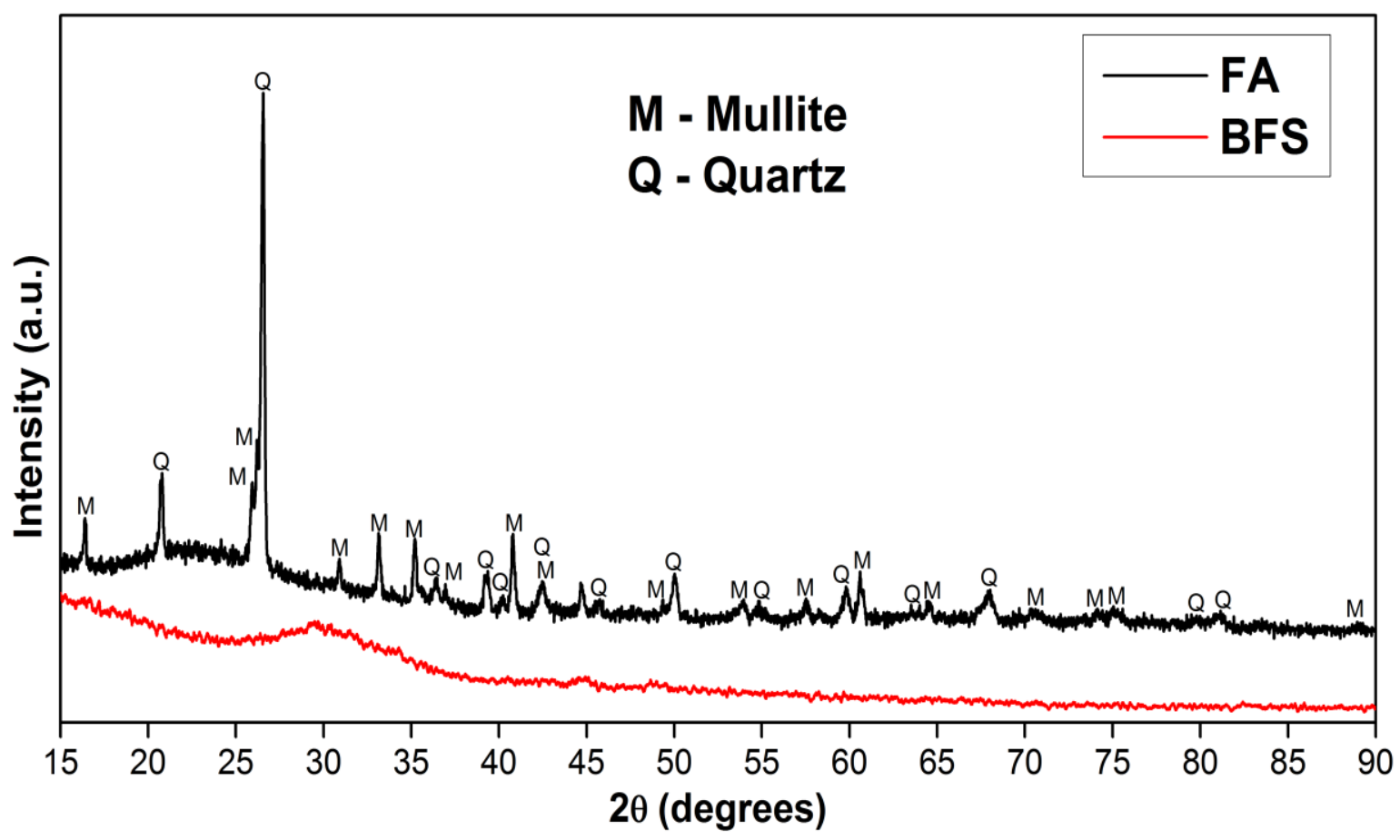

Figura 4: Patrones de difracción de rayos X de los polvos cementantes FA y BFS.

Los diferentes sistemas binarios activados con ceniza de cascarilla de arroz y silicato de sodiodan lugar a los patrones de difracción presentados en las Figuras 5Erro! Fonte de referência não encontrada. y 6 , respectivamente. El análisis del patrón de difracción de la ceniza de cascarilla de arroz (CCA) muestra en la Figura 5 la presencia de una banda de amplitud considerable en el rango $2 \theta \approx 19^{\circ}-24^{\circ}$, correspondiente a la sílice en fase amorfa [14], y además, Cristobalita ( $\mathrm{SiO}_{2}, \mathrm{COD}$ Reference Code 96-900-8111) como fase cristalina predominante en el activante [15].

Como se muestra en la Figura 5 para las mezclas activadas con CCA, a mayores contenidos de escoria de alto horno, la intensidad de las señales representativas de las fases cristalinas presentes tanto en la ceniza volante como en la CCA, se atenúa, esto ocasionado por el carácter amorfo de la escoria. No obstante, la presencia de esos picos iniciales remanentes en el difractograma indica que luego de la activación alcalina los cementantes no fueron completamente disueltos. Para todos los sistemas binarios activados se presentan fases cristalinas de Cuarzo y Mullita, que se deben al aporte de la ceniza volante. Como productos de reacción aparecen señales características de compuestos tipo gel C-H-S, las cuales aunque exhiben baja cristalinidad debido al amplio rango ocupado por la señal, evidencian la ocurrencia de la reacción entre el material amorfo reactivo presente en la escoria y el material del mismo tipo presente en la ceniza de cascarilla de arroz $(\mathrm{CaO}-$ $\mathrm{SiO}_{2}-\mathrm{H}_{2} \mathrm{O}$ ) [16] lo cual aporta el desarrollo de resistencias mecánicas en cada mezcla. Fue observado también un polimorfismo conocido como Clinotobermorite (COD Reference Code 1000046) [17]. Además se generó otra fase cristalina de tipo aluminosilicato $\left(\mathrm{Al}_{11.52} \mathrm{Si}_{24.48} \mathrm{O}_{72}\right.$, COD Reference Code 96-901-6279), presente únicamente en la mezcla con mayor contenido de ceniza volante, 80FA-20BFS. Cabe resaltar que para esa mezcla con menor contenido de escoria (80FA-20BFS) ocurren dos situaciones particulares: i) se genera una atenuación considerable de la señal característica del gel C-S-H ubicada en $2 \theta=29,1^{\circ}$, acompañada del corrimiento hacia valores mayores, de la señal de gran amplitud que representa a la sílice amorfa de la ceniza volante, suceso que evidencia la formación del gel tipo N-A-S-H [18], y ii) se presenta una señal de cristobalita en la ubicación $2 \theta=27,97^{\circ}$, probablemente correspondiente al material cristalino originario de la ceniza de cascarilla de arroz que no tomó parte en la reacción de formación del gel C-S-H. Sin embargo, Hart et al. [19] afirman quelas fases cristalinas que no se envuelven en la reacción, simplemente se presentan como filler o llenantes no reactivos en la matriz ligante, lo cual de alguna forma puede contribuir al desarrollo de las resistencias mecánicas para la mezcla 80FA-20BFS. 


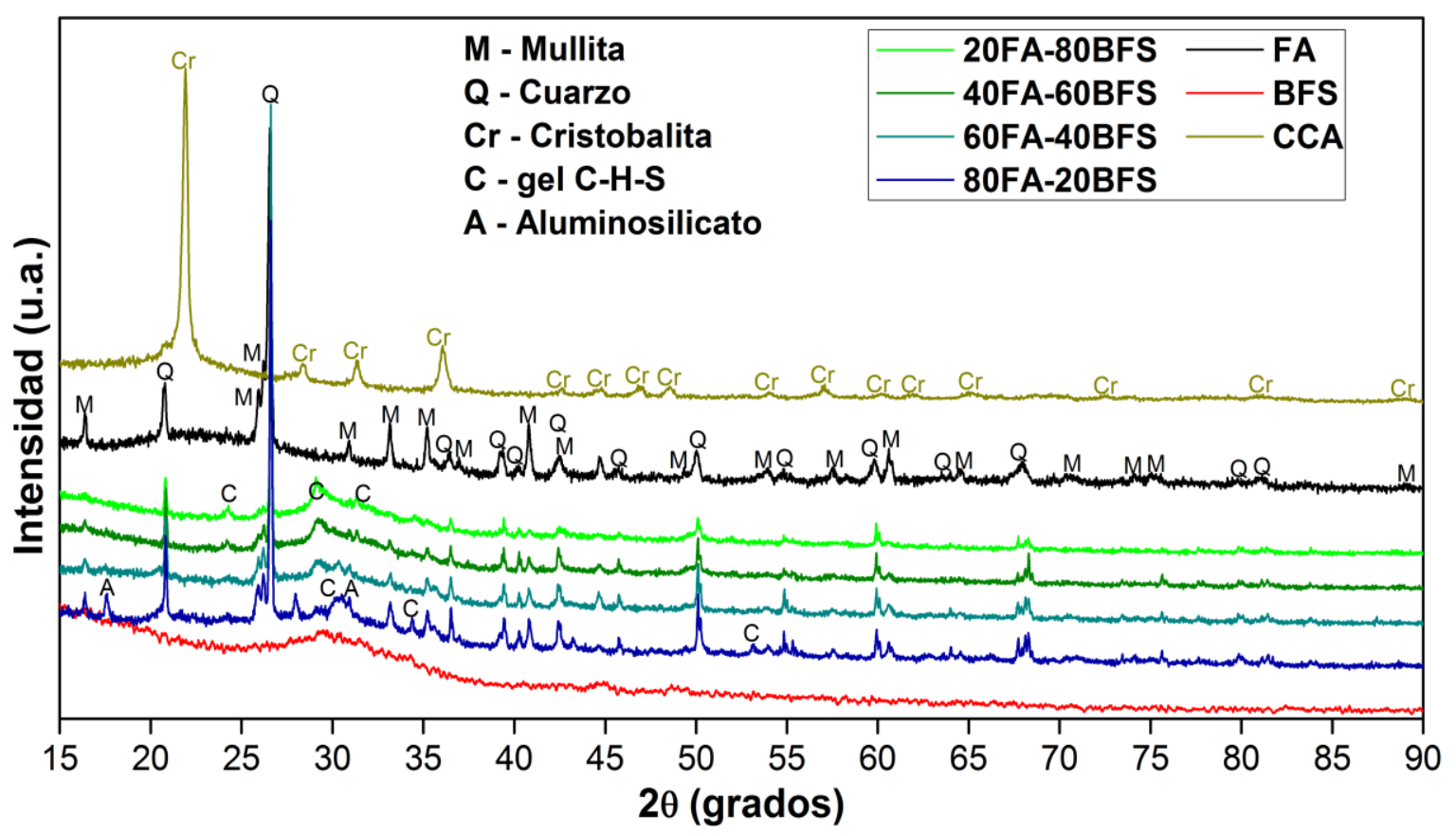

Figura 5: Patrones de difracción de rayos $X$ para los polvos cementantes y los sistemas binarios activados con CCA.

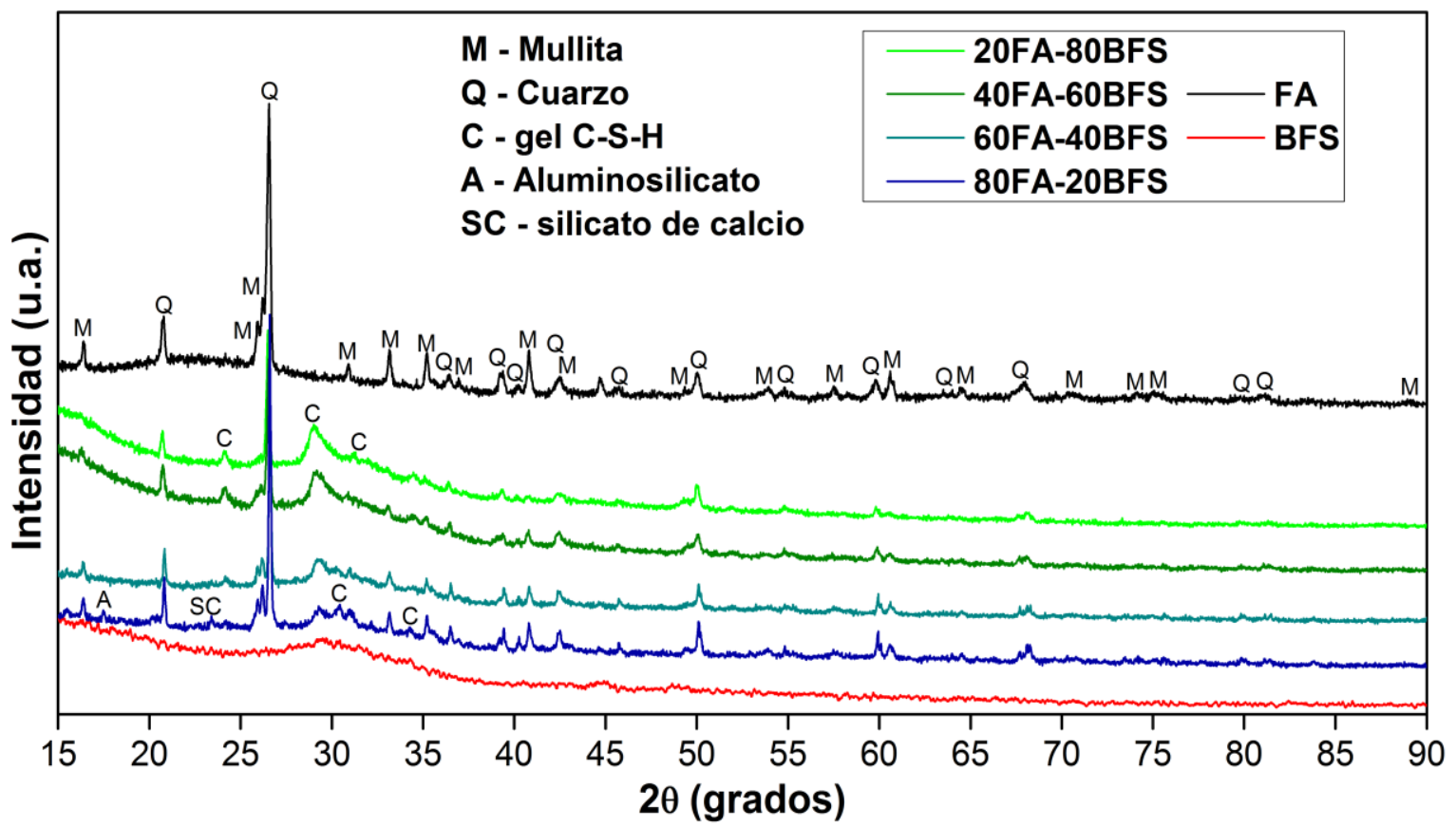

Figura 6: Patrones de difracción de rayos $X$ para los polvos cementantes y los sistemas binarios activados con $\mathrm{Na}_{2} \mathrm{SiO}_{3}$.

Los patrones de difracción obtenidos para las mezclas activadas con silicato de sodio $\left(\mathrm{Na}_{2} \mathrm{SiO}_{3}\right)$ y mostrados en la Figura 6, muestran la presencia de las fases cristalinas Cuarzo y Mullita, propias de la ceniza volante, aunque atenuadas debido al fuerte aporte de material amorfo generado por la escoria de alto horno. Se presentan señales características de gel tipo C-S-H (Clinotobermorite) de igual manera que para las mezclas activadas con CCA, principalmente en las mezclas con alto contenido de escoria. Por otra parte las señales atribuidas a fases cristalinas de tipo aluminosilicato son grandemente atenuadas para esta conjunto de mezclas activadas $\mathrm{Na}_{2} \mathrm{SiO}_{3}$, siendo en algunos casos reemplazadas por señales correspondientes a productos de tipo C-S-H. Con respecto a la señal ubicada en $2 \theta=27,97^{\circ}$, que se presentaba en la mezcla con menor contenido de escoria, es decir 80FA-20BFS activada con CCA, se evidencia su desaparición, concluyendo de 
esta manera que esta correspondía a material cristalino (Cristobalita) sin reaccionar, proveniente de la ceniza de cascarilla de arroz. Se resalta por último la presencia de una señal ubicada en $2 \theta=23,37^{\circ}$ para la mezcla activada con $\mathrm{Na}_{2} \mathrm{SiO}_{3}$, correspondiente a silicato de calcio $\left(\mathrm{O}_{20} \mathrm{Ca}_{10} \mathrm{Si}_{4}\right.$, COD Reference Code 96-152-9965).

Con el objetivo de cuantificar el contenido de material amorfo presente en las diferentes mezclas, sobre pastas representativas se aplicó el método del estándar externo, utilizando como estándar una mezcla $100 \%$ cristalina de las fases rutilo y anatase del óxido de titanio. En la Figura 7 se muestran los valores obtenidos para contenido amorfo presente en las mezclas, y en la Tabla 4 se presentan los porcentajes de cada una de las fases cristalinas existentes.Como se muestra en la Figura 7 y en la Tabla 4, las mezclas activadas con CCA, presentan los mayores contenidos de material amorfo, resultado que permite inferir que la reacción alcalina que se da entre la CCA y los materiales cementantes, no solo produce estructuras cristalinas como la Clinotobermorite, sino que también se da la formación de geles C-A-S-H y N-A-S-H de tipo amorfo [20], los cuales cual repercuten en el mejoramiento de las propiedades mecánicas de los morteros.

Tabla 4: Contenido cristalino presente en los sistemas binarios analizados.

\begin{tabular}{|c|c|c|c|c|c|}
\hline & IDENTIFICACIÓN & $\begin{array}{c}\text { MULLITA } \\
\%\end{array}$ & $\begin{array}{c}\text { CUARZO } \\
\%\end{array}$ & $\begin{array}{c}\text { CLINOTOBERMORITA } \\
\%\end{array}$ & OTROS \\
\hline \multirow{4}{*}{$\begin{array}{c}85 \% \mathrm{NaOH} \\
15 \% \mathrm{CCA}\end{array}$} & FA8-BFS2 & 4,6 & 5,3 & 0,3 & Alumino silicato: $1,2 \%$ \\
\hline & FA6-BFS4 & 3,0 & 5,5 & 3,6 & - \\
\hline & FA4-BFS6 & 2,3 & 4,4 & 4,0 & - \\
\hline & FA2-BFS8 & 2,5 & 3,0 & 4,4 & - \\
\hline \multirow{4}{*}{$\begin{array}{c}85 \% \mathrm{NaOH} \\
15 \% \mathrm{Na}_{2} \mathrm{SiO}_{3}\end{array}$} & FA8-BFS2 & 5,4 & 5,4 & 2,3 & Silicato de calcio: $1,6 \%$ \\
\hline & FA6-BFS4 & 3,8 & 4,1 & 4,6 & - \\
\hline & FA4-BFS6 & 3,3 & 5,3 & 5,9 & - \\
\hline & FA2-BFS8 & 1,7 & 4,5 & 5,8 & - \\
\hline
\end{tabular}

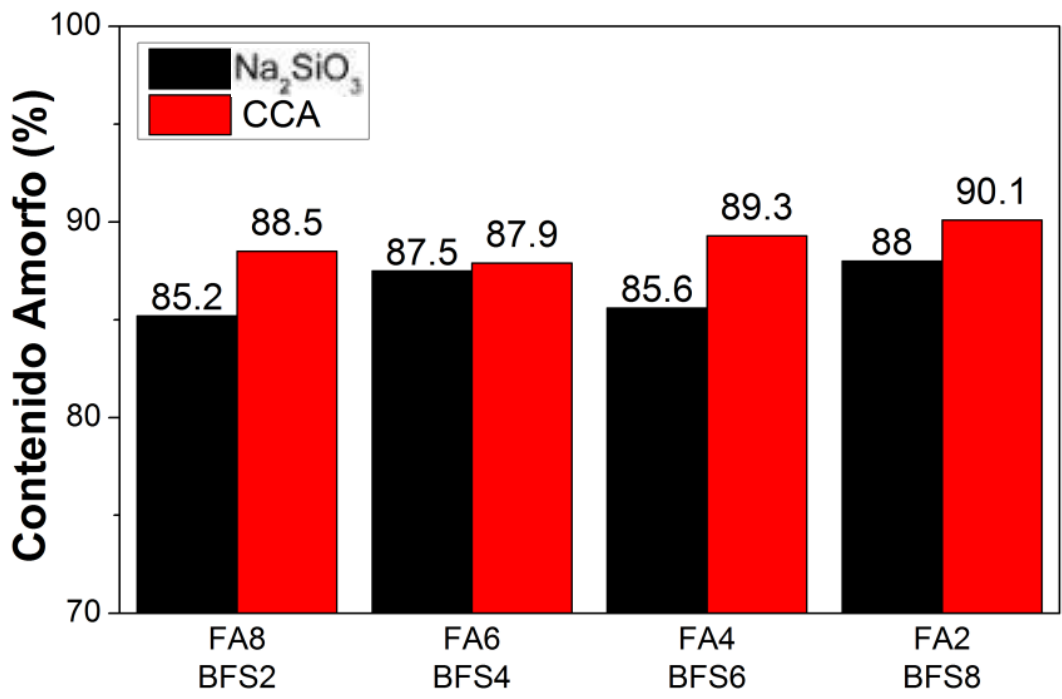

Id. Mezcla

Figura 7: Contenido amorfo para los sistemas binarios activados con CCA y Na2SiO3.

\subsection{Resistencia a compresión}

Los resultados de los ensayos de resistencia a compresión a 28 días, $\boldsymbol{f}_{\boldsymbol{c}}$, sobre los especímenes cúbicos activados por la ceniza de cascarilla de arroz y el silicato de sodio se relacionan en la Figura 8. Las tendencias obtenidas en resistencia a compresión de los morteros con ceniza de cascarilla de arroz y silicato de sodio se muestran en la Figura 9. 


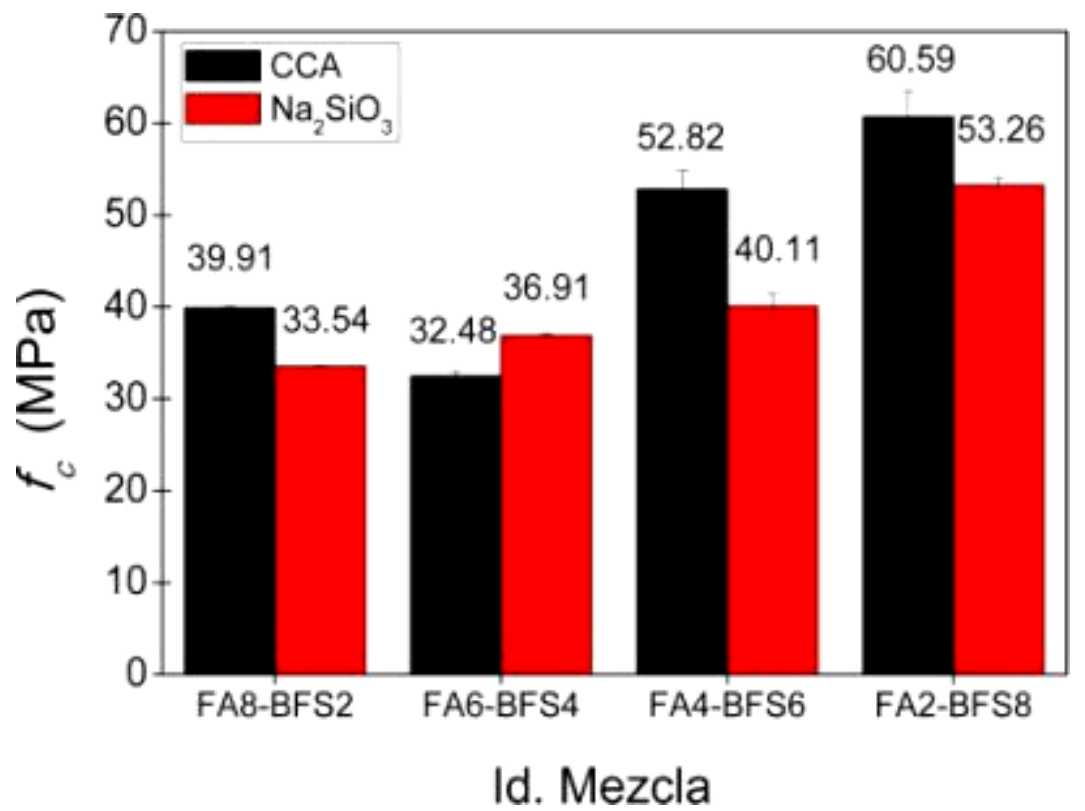

Figura 8: Resultados de resistencia a compresión para los sistemas binarios activados con cenizas de cascarilla de arroz (CCA) y silicato de sódio $\left(\mathrm{Na}_{2} \mathrm{SiO}_{3}\right)$.
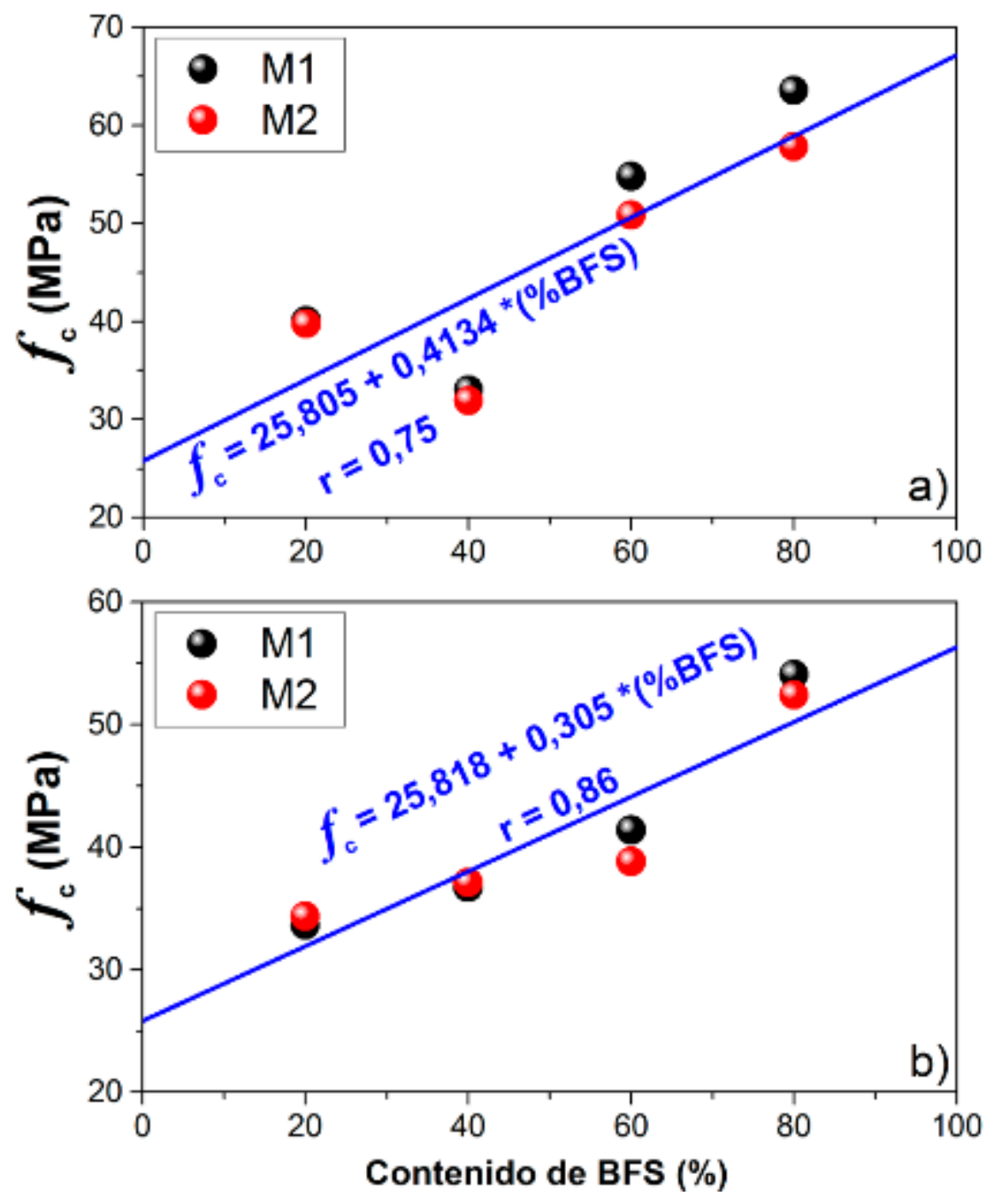
Figura 9: Tendencias en compresión para los sistemas binarios activados con: a) CCA, b) Na2SiO3.

Como se observa en la Figura 8 para las mezclas activadas con ceniza de cascarilla de arroz, la resistencia a compresión de los especímenes aumentó en función del incremento del contenido de escoria en las mezclas. De acuerdo con la Figura 8, la mezcla con mayor contenido de escoria, esto es, FA2-BFS8, resultó ser de entre las 4 mezclas evaluadas la de mayor desempeño en compresión con una resistencia promedio de 60,69 MPa. No obstante, a pesar que la mezcla FA6-BFS4 presentara el valor de resistencia promedio 32,48 MPa como el valor en compresión más bajo de todas las mezclas, en general se evidencia una tendencia lineal al aumento con mayores porcentajes de escoria, como se muestra en la Figura 9a. Como se observa en la Figura 9a, la utilización del $80 \%$ de escoria de alto horno en las mezclas (FA2-BFS8) provoca un incremento de aproximadamente $50 \%$ de las resistencias a compresión en comparación a las resistencias proporcionadas por la mezcla con el $20 \%$ de escoria de alto horno (FA8-BFS2). En consecuencia, se demuestra el efecto benéfico que proporciona la escoria de alto horno sobre el desempeño en compresión de los sistemas binarios evaluados en este estudio, donde las resistencias mecánicas son basadas en la formación y coexistencia de los geles tipo aluminosilicato alcalino hidratado (N-A-S-H) y silicoaluminato cálcico hidratado (C-A-S-H) propios de la ceniza volante y escoria de alto horno, respectivamente.

También Mejía et al. [8] estudiaron la viabilidad al utilizar la ceniza de cascarilla de arroz como reemplazo total del silicato de sodio comercial en sistemas binarios ceniza volante/escoria de alto horno y concluyen que el uso de la ceniza de cascarilla de arroz como reemplazo total del silicato de sodio no presenta mayor incidencia en el tipo de productos de reacción. En el presente estudio, se afirma que las morteros de ceniza volante/escoria de alto horno no son afectados negativamente por la inclusión de ceniza de cascarilla de arroz, por el contrario, los resultados en compresión mostrados en la Figura 8 elucidan desempeños mecánicos competentes para este tipo de materiales. El contenido de sílice amorfa de la CCA participa de forma activa en los procesos de activación alcalina, considerando que el contenido cristalino de la CCA puede actuar como filler en la microestructura, incrementando la densidad de los morteros. Esta sinergia entre el contenido amorfo y contenido cristalino de la CCA provocan las mayores resistencias a compresión (ver Figura 8).

Referente a las mezclas binarias activadas con silicato de sodio, como se observa en las Figuras 8 y $9 \mathrm{~b}$, la resistencia a compresión de los especímenes incrementa linealmente con el aumento del porcentaje de escoria de alto horno, de tal forma que las tendencias en compresión de los especímenes activados con silicato de sodio fueron similares a las observadas en los especímenes activados con ceniza de cascarilla de arroz. Precisamente para las mezclas activadas con silicato de sodio, se presentó la mayor resistencia a compresión 53,46 MPa para la mezcla FA2-BFS8 de mayor contenido de escoria de alto horno, y la menor resistencia a compresión de 33.99 MPa para la mezcla FA8-BFS2 con el menor contenido de escoria. Lo anterior permite concluir que el incremento máximo de resistencias a compresión para las mezclas binarias con silicato de sodio fue de 36\%, al comparar las resistencias observadas para las mezclas FA2-BFS8 y FA8-BFS2. Sin embargo, si son confrontados los incrementos en compresión máximos desarrollados en las mezclas con silicato de sodio (36\%) y las mezclas con ceniza de cascarilla de arroz (50\%), es evidente que las mezclas activadas con ceniza de cascarilla de arroz, a pesar de presentar una menor fluidez en estado fresco como lo muestra la Figura 3, promueven mayores aumentos de resistencias mecánicas. Como lo muestran las tendencias de la Figura 3, la fluidez de los morteros con silicato de sodio y cenizas de cascarilla de arroz corresponde a una consistencia normal para bajos contenidos de ceniza volante, e incrementa gradualmente con mayores contenidos de escoria adicionados a los morteros. Sin embargo, la menor fluidez de los morteros activados con cenizas de cascarilla de arroz, de acuerdo con las tendencias de la Figura 3, se debe a las menores relaciones $\mathrm{Na}_{2} \mathrm{O} / \mathrm{H}_{2} \mathrm{O}$ obtenidas para este tipo de mezclas, en comparación con las relaciones $\mathrm{Na} \mathrm{a}_{2} \mathrm{O} / \mathrm{H}_{2} \mathrm{O}$ obtenidas para los moteros con silicato de sodio (Tabla 3 ).

Como se observa en las Figuras 8 y 9, los desempeños en compresión para las mezclas con ceniza de cascarilla de arroz fueron mayores a los desempeños en compresión aportados por las mezclas con silicato de sodio: en este estudio fueron observadas diferencias de hasta $24 \%$ en favor de las mezclas con ceniza de cascarilla de arroz, particularmente para la mezcla FA4-BFS6. Esos desempeños mecánicos superiores para las mezclas activadas con ceniza de cascarilla de arroz pueden atribuirse a la inclusión de fuentes adicionales de sílice para el crecimiento de los geles N-A-S-H y C-A-S-H, y a la presencia de nuevas partículas sólidas en la matriz que ocupan las porosidades del sistema ceniza volante/escoria generando una estructura más densificada y provocando un refinamiento en la red de poros del sistema, lo que por obvias razones no es apreciado en las mezclas activadas con silicato de sodio.Hwang y Huynh [21] afirman que la resistencia a compresión de la red tetraédrica de aluminosilicatos incrementa con el aumento en los contenidos de ceniza de cascarilla de arroz y concluyen que los incrementos mecánicos son debidos a: (i) el aumento en la cantidad de sílice reactiva de las adiciones de ceniza de cascarilla de arroz que resulta en enlaces Si-O-Si de alta densidad, y (ii) 
un alto contenido de ceniza de cascarilla de arroz con una alta superficie específica hacen a los productos finales más dúctiles. Igualmente el efecto incremental de las resistencias mecánicas por el uso de cenizas de cascarilla de arroz ha sido reportado en otros estudios [5,22].

Como se ha mencionado, el presente estudio evidencia las mayores resistencias a compresión para los sistemas ceniza volante/escoria activados con ceniza de cascarilla de arroz, superando el desempeño alcanzado por los mismos sistemas de activación con silicato de sodio. Cabe señalar que para este estudio se utilizó una cantidad de ceniza de cascarilla de arroz correspondiente al $15 \%$ del peso total en la solución activante, como se describe en el programa experimental, cantidad que los autores consideran como mínima si se compara con relación a los contenidos de ceniza volante y escoria en cada sistema (aprox. 6\% del precursor). No obstante, se espera que incrementos de ceniza de cascarilla de arroz generen, luego de un óptimo contenido, la eventual reducción en el desempeño mecánico de los sistemas evaluados (ceniza volante/escoria de alto horno), debido al exceso de iones Si y su incompleta disolución en la microestructura, como lo validan previos estudios [5,21]. En dosificaciones apropiadas, de esta manera, se afirma que la ceniza de cascarilla de arroz como fuente alternativa de sílice en sistemas ceniza volante/escoria de alto horno es capaz de garantizar condiciones para la activación de los precursores, como lo confirman los resultados de Difracción de rayos X caracterizados sobre los especímenes. Las tendencias señaladas justifican el motivo por el cual se generan mayores desempeños mecánicos (resistencia a compresión) para los sistemas activados con ceniza de cascarilla de arroz, en comparación a los sistemas activados con silicato de sodio comercial.

\subsection{Modelos de predicción}

A partir de las tendencias de los resultados medidos, en la Tabla 5 se proponen modelos de predicción de los parámetros evaluados para los sistemas ceniza volante/escoria de alto horno, en función de las adiciones de escoria de alto horno (\% BFS), y en la Tabla 6 se presentan las constantes empleadas en dicha determinación. La dispersión de estos parámetros fue evaluada mediante el coeficiente de correlación r, definido como un indicador de la intensidad de la relación lineal entre los valores estimados y los resultados experimentales. Con base en los valores $\mathrm{r}$ de las ecuaciones, se puede afirmar que los modelos de predicción propuestos son adecuados, ya que estos valores varían entre 0,75 y 0,96 ; es decir, son cercanos a 1 . Lo anterior indica que existe una estrecha relación entre los parámetros observados y los calculados.

Tabla 5: Ecuaciones propuestas para la determinación de las propiedades mecánicas de las mezclas binarias.

\begin{tabular}{clc}
\hline PROPIEDAD & ECUACIÓN PROPUESTA & UNIDAD \\
\hline Fluidez & $f l=[\mathrm{A}(\% \mathrm{BFS})+\mathrm{B}]$ & $\%$ \\
\hline Resistencia a compresión & $f_{c}=[\mathrm{A}(\% \mathrm{BFS})+\mathrm{B}]$ & $\mathrm{MPa}$ \\
\hline
\end{tabular}

Tabla 6: Constantes de las ecuaciones propuestas para la determinación de las propiedades mecánicas de los morteros.

\begin{tabular}{ccccc}
\hline \multirow{2}{*}{ PARÁMETRO } & TIPO DE MEZCLA & \multicolumn{2}{c}{ CONSTANTE } & $\begin{array}{c}\text { COEFICIENTE } \\
\text { DE } \\
\text { CORRELACIÓN }\end{array}$ \\
\cline { 2 - 4 }$f l$ & Activación con CCA & 0,6839 & $-4,720$ & $r=0,94$ \\
\cline { 2 - 4 } & Activación con $\mathrm{Na}_{2} \mathrm{SiO}_{3}$ & 0,7095 & 0,040 & $r=0,96$ \\
\hline \multirow{2}{*}{$f_{c}$} & Activación con $\mathrm{CCA}_{n}$ & 0,4134 & 25,800 & $r=0,75$ \\
\cline { 2 - 4 } & Activación con $\mathrm{Na}_{2} \mathrm{SiO}_{3}$ & 0,3079 & 25,719 & $r=0,86$ \\
\hline
\end{tabular}

\section{CONCLUSIONES}

Con base en los resultados obtenidos para los ensayos realizados, fueron evaluados algunos efectos de la ceniza de cascarilla de arroz como fuente de sílice alternativa en sistemas cementantes binarios ceniza volante/escoria de alto horno, y se proponen ecuaciones que permiten representar dicho comportamiento. Los resultados del presente estudio permiten concluir lo siguiente: 
Los sistemas binarios ceniza volante/escoria activados con ceniza de cascarilla de arroz y silicato de sodio presentan contenidos principalmente amorfos que favorecen las reacciones químicas de endurecimiento y las propiedades mecánicas de los morteros. El pequeño porcentaje de contenido cristalino existente en los sistemas se debe en primera medida al material cristalino que no participa en las reacciones alcalinas y que pertenece a los polvos cementantes originales, y en segunda instancia a la formación de aluminosilicatos, silicatos de calcio y gel CSH semicristalino, los cuales son productos de la reacción presentes en las matrices reaccionadas.

A pesar de la menor fluidez, los sistemas binarios ceniza volante/escoria de alto horno activados con ceniza de cascarilla de arroz presentaron resistencias a compresión de hasta $61 \mathrm{MPa}$ en 28 días, superiores a las resistencias presentadas por los mismos sistemas activados con silicato de sodio. Estos desempeños mecánicos superiores son posiblemente debidos a la inclusión de fuentes adicionales de sílice para el crecimiento de los geles N-A-S-H y C-A-S-H, y a la presencia de nuevas partículas sólidas en la matriz que ocupan las porosidades del sistema ceniza volante/escoria generando una estructura más densificada y provocando un refinamiento en la red de poros de la misma. Por lo tanto, se afirma que la ceniza de cascarilla de arroz como fuente alternativa de sílice en sistemas binarios ceniza volante/escoria de alto horno garantiza condiciones adecuadas para la activación de los precursores.

Las ecuaciones propuestas aplican para sistemas binarios de activación alcalina empleando cenizas volantes clase $\mathrm{F}$ y escorias de alto horno en diferentes dosificaciones, activados mediante la combinación $85 \% \mathrm{NaOH} 14 \mathrm{M}$ y $15 \%$ ceniza de cascarilla de arroz /silicato de sodio, y resistencias a compresión a 28 días entre 32 y $61 \mathrm{MPa}$. No obstante, aunque los resultados pueden variar de acuerdo a la naturaleza de las cenizas y escorias, y al tipo de curado utilizado, dichas ecuaciones ilustran en general el comportamiento en las propiedades de fluidez y resistencia a compresión para morteros.

El presente estudio comprueba que si es viable la utilización de cenizas de cascarilla de arroz como fuente alternativa de sílice en sistemas de activación alcalina, en este caso, para la activación de sistemas binarios basados en combinaciones ceniza volante/escoria de alto horno. Así, la total sustitución del silicato de sodio por cenizas de cascarilla de arroz, contribuye a la reducción de los contaminantes generados por la fabricación del silicato de sodio y a una adecuada disposición de las cenizas de cascarilla de arroz tan abundantes en nuestro entorno.

\section{AGRADECIMENTOS}

A la Vicerrectoría de Investigaciones de la Universidad Militar Nueva Granada por el financiamiento del proyecto ING 2100. Particularmente, el autor Jhon Cárdenas Pulido agradece a la entidad COLCIENCIAS por el financiamiento de la Convocatoria 645 de 2014, y de la misma forma el autor Manuel J. Pinzón agradece a la entidad COLCIENCIAS por el financiamiento de la Convocatoria 706 de 2015 - Jóvenes Investigadores. El autor Willian Aperador agradece al Proyecto Prometeo de la Secretaría de Educación Superior,Ciencia, Tecnología e Innovación de la república de Ecuador. Finalmente agradecimientos a las compañías Acerías Paz del Río y Planta Eléctrica de Sochagota (Termopaipa IV) por la donación delos materiales de escoria y ceniza volante suministrados.

\section{BIBLIOGRAFIA}

[1] TCHAKOUTÉ, H.K., RÜSCHER, C.H., KONG, S., et al., "Synthesis of sodium waterglass from white rice husk ash as an activator to produce metakaolin-based geopolymer cements", Journal of Building Engineering, v. 6, pp. 252-261, June 2016.

[2] PALOMO, A., GRUTZECK, M.W., BLANCO, M.T. "Alkali-activated fly ashes: a cement for the future," Cement and Concrete Research, v. 29, n. 8, pp.1323-1329, August 1999.

[3] BERNAL, S.A, RODRÍGUEZ, E.D., MEJÍA DE GUTIÉRREZ, R., et al., "Activation of metakaolin/slag blended alkaline solutions based on chemically modified silica fume and rice husk ash," Waste Biomass Valor, v. 3, n.1, pp. 99-108, October 2011.

[4] NOVOTNY, R., HOFF, A., SCHUERTZ, J., "Process for hydrothermal production of sodium silicate solutions," United States Patent, 1991, 5,000, 933.

[5] DUXSON, P., MALliCOAT, S.W., LUKEY, G.C., et al., "The effect of alkali and Si/Al ratio on the development of mechanical properties of metakaolin-based geopolymers", Colloids and Surfaces A: Physicochemical and Engineering Aspects, v. 292, n. 1, pp. 8-20, January 2007. 
[6] KAMSEU, E., MOUNGAM, L.M., CANNIO, M., et al., "Substitution of sodium silicate with rice rusk ash-NaOH solution in metakaolin based geopolymer cement concerning reduction in global warming", Journal of Cleaner Production, v. 142, n. 4, pp.3050-3060, 2017.

[7] POOWANCUM, A., NIMWINYA, E., HORPIBULSUK, S., "Development of room temperature curing geopolymer from calcined water-treatment-sludge and rice husk ash",Calcined Clays for Sustainable Concrete, pp. 291-297, 2015.

[8] MEJÍA J.M., MEJÍA DE GUTIERREZ, R., PUERTAS, F. "Rice husk ash as a source of silica in alkaliactivated fly ash and granulated blast furnace slag systems," Materiales de Construcción, v. 63, n. 311, pp. 361-375, 2013.

[9] CRIADO, M., FERNANDEZ-JIMENEZ, A., DE LA TORRE, A.G., ARANDA, M.A.G., PALOMO, A., "An XRD study of the effect of the $\mathrm{SiO} 2 / \mathrm{Na} 2 \mathrm{O}$ ratio on the alkali activation of fly ash," Cement and Concrete Research, v. 37, no.5, pp. 671-679, May 2007.

[10] FICHA DE DATOS DE SEGURIDAD PANREAC LENTEJAS PA-ACS-ISO. PANREAC QUÍMICA S.L.U., Barcelona, España, 2001.

[11] ASTM C 109M-16, Standard test method for compressive strength of hydraulic cement mortars (using 2-in. or [50-mm] cube specimens), v. 04.01, Philadelphia (EE.UU.): American Society of Testing and Materials (ASTM), 2016.

[12] ASTM C 1437-15, Standard test method for flow of hydraulic cement mortar, v. 04.01, Philadelphia (EE.UU.): American Society of Testing and Materials (ASTM), 2015.

[13] HEMMINGS, R.T., BERRY, E.E., "On the glass in coal fly ashes: recent advances”, MRS Proceedings, v. 113, pp. 3-38, 1987.

[14] NAIR, D.G., FRAAIJ, A., KLAASSEN,A.A.K., et al., "A structural investigation relating to the pozzolanic activity of rice husk ashes", Cement and Concrete Research, v. 38, n. 6, pp. 861-869, June 2008.

[15] SIDDIQUE, R., KHAN, M.Supplementary Cementing Materials, v.37, Berlín, Springer, 2011.

[16] YU, Q., SAWAYAMA, K., SUGITA, S., et al., "The reaction between rice husk ash and $\mathrm{Ca}(\mathrm{OH}) 2$ solution and the nature of its product", Cement and Concrete Research, v. 29, n. 1, pp. 37-43, January 1999.

[17] CRIADO, M., APERADOR, W., SOBRADOS, I.., "Microstructural and Mechanical Properties of Alkali Activated Colombian Raw Materials, Materials (Basel), v. 9, n. 3, 2016.

[18] ROVIELLO, G., RICCIOTTI, L., TARALLO, O., et al., "Innovative fly ash geopolymer-epoxy composites: preparation, microstructure and mechanical properties”, Materials (Basel), v. 9, n. 6, 2016.

[19] HART, R.D., LOWE, J.L., SOUTHAM, D.C., PERERA, D.S., WAL, P., "Aluminosilicate inorganic polymers from waste materials", Green Processing, Newcastle, Australia, 2006.

[20] RICHARDSON, I., GROVES, G., "The structure of the calcium silicate hydrate phases present in hardened pastes of white Portland cement/blast-furnace slag blends", Journals of Materials Science, v. 32, n. 18, pp. 4793-4802, September 1997.

[21] HWANG, C.L., HUYNH, T.P., "Effect of alkali-activator and rice husk ash content on strength development of fly ash and residual rice husk ash-based geopolymers," Construction and Building Materials, v. 101, n.1, pp.1-9, December 2015.

[22] BOUZÓN, N., PAYÁ, J., BORRACHERO, M. V., et al., "Refluxed rice husk ash/NaOH suspension for preparing alkali activated binders," Materials Letters, v. 115, n. 15, pp. 72-74, January 2014.

\section{ORCID}

Jhon Cárdenas Pulido

William Aperador

Michel Ospina

Kervin chunga

Jhon Aperador

Manuel Pinzon https://orcid.org/0000-0003-4698-4896

https://orcid.org/0000-0003-1778-0851

https://orcid.org/0000-0002-5208-8943

http://orcid.org/0000-0002-2286-1843

https://orcid.org/0000-0001-9907-5157

https://orcid.org/0000-0001-5572-4856 